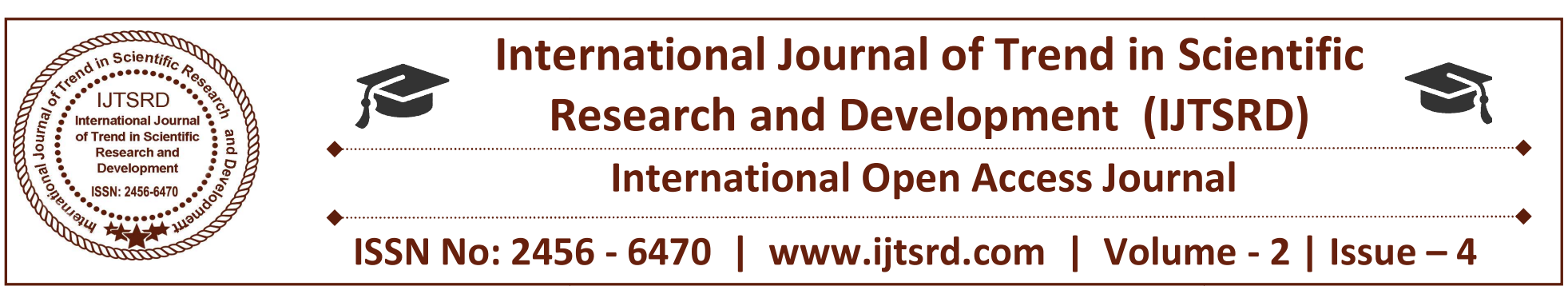

\title{
A Study on Future Talent Acquisition with Reference to e-Recruitment Practices Followed in it and ITeS Companies
}

\author{
Narmadha. M. $\mathbf{P}^{1}$, Dr. M. R. Vanithamani ${ }^{2}$ \\ ${ }^{1} \mathrm{Ph} . \mathrm{D}$ Scholar, Bharathiar University, Coimbatore, Tamil Nadu, India \\ ${ }^{2}$ Professor, Department of Management Studies, Dhanalakshmi Srinivasan College of Engineering, Coimbatore
}

\begin{abstract}
\end{abstract}
This is a conceptual paper to study about the concept of electronic Recruitment, usage of social media network sites in e recruitment, forms of recruitment in organization and the advantages and disadvantages of e-recruitment. The most crucial sources of competitive advantage are based on human resource efforts through attracting and retaining talented individuals. The internet has helped in attracting potential candidates to an organization from the recruitment process, which is referred to as ERecruitment. The practice of issuing a vacant position and applying for a job via a website has increased steadily. The purpose of this paper is to broaden the research on the recruitment practices, with focus on E-Recruitment practices and trends in India with respect to IT sector, to identify what e-recruitment methods are being used and what benefits are being experienced by organizations using these methods. Many organizations have already employed erecruitment processes for posting jobs and accepting resumes on internet and corresponding with applicants through e-mails. This paper aims to discuss the concept, nature, problems, benefits, methods and trends and conditions for good electronic recruitment.

\section{INTRODUCTION}

The world of recruitment is undergoing rapid transformation. Mass adoption of new tools and technologies has made the talent acquisition process data rich and workflow friendly. More and more organizations are now shifting their recruitment strategy to digital domain. E-Recruitment or online Recruitment is the process of personnel recruitment using electronic resources, in particular the internet.
E-recruitment can be divided into two types of uses: corporate web site for recruitment and commercial jobs boards (such as monster.com) for posting job advertisements. Organizations have cut costs by almost 80 percent over traditional recruitment modes by moving over to the online recruitment process." Dhruvakanth B Shenoy, Vice President-Marketing, Asia, Monster.com, India. Corporate websites are a company's own website with a link for job posting/career options where candidates can log into for current openings. If the company advertises its vacant positions on other website that specialize in recruitment such as - naukri.com, timesjob.com, monster.com, etc., the companies would be adopting commercial job boards for recruitment. Companies and recruitment agents have moved much of their recruitment process online so as to improve the speed by which candidates can be matched with live vacancies. Using database technologies, and online job advertising boards and search engines, employers can now fill posts in a fraction of the time previously possible. Using an online e-Recruitment system may potentially save the employer time as usually they can rate the e Candidate and several persons in HR independently review e Candidates The applicants send their resumes via social networking sites that help in paper less recruitment process in human resource functions. So that E-recruitment is more effective in today world scenario.

\section{LITERATURE REVIEW}

A research conducted by Verhoeven and Williams (2008) news on learning into e-recruitment and selection. The study focused on the advantages and 
disadvantages as acknowledged in literature and considered those against the views of HR Managers in. An analysis conducted by Williams (2009) on Erecruitment showed declining recruitment spends focused on web-based recruitment at the expense of traditional methods. Online methods proved far more popular of the HR professionals surveyed said that the jobs sector of their own company's website was used as a recruitment instrument for many jobs. The results from Holm's (2012) thesis were that there was a disparity among the paper-based and the electronicbased recruitment method.

The electronic-based recruitment process began with few electronic tools for line managers to begin the recruitment process, e.g. line managers were putting their hiring needs into a Word document and sending it to the accountable recruiter. The recruiter then had to read each applicant and rate the order. In some cases, this is handled through filter programs bringing top applicants to the forefront. Ms. D Shahila (2013) The study helps to investigate the trends in erecruitment, its apply and practice, e-recruitment methods, E-Recruitment Challenges and issues as well as its growing scope in the recruitment process of a business. It also converses the main success factors of e-recruitment are the value-added services provided by the job sites, cost efficiency, rapidity, providing modified solutions, serving to institute dealings with HR managers and assist image building of the companies.

Forms of Recruitment There are mainly two forms/methods of recruitment. Centralized Decentralized In centralized recruitment the organization is having a devoted central department for recruitment process and the concerned departments do not participate in decision making. Organization like state bank of India employs central recruitment process. Decentralized recruitment is having authority to each department to choose their own staff. The companies which are geographically spread or very big in size find this form convenient. General Electric Company follows this method. Cost benefit analysis determines the source of recruitment. There's another method too. Internal sources could restrict the number of suitable candidates for the available position. External search could be employee referrals, campus recruitment, placement agencies, off payroll candidates and advertisements.

Effective management development of human resources has long been acknowledged by both scholars and practitioners as being a key component to the overall success of the business. Recruitment is just one element of human resource management and development; however, it is significant to this success as it is the method used to acquire the human capital for the organization. Recruitment and selection is necessary human resource processes initiated by organization where the constant balancing and is to find and retain quality staff that meet the needs of the position and the company whilst minimizing expenditure in the process of hiring manpower.

The majority researchers agree that recruitment is not a one-way process, but rather a complex, two-way process. Whilst employers focus on looking attractive to a potential job applicant, the applicant is continuing from the initial recruitment process through to the final appointment outcome.Most of the organization and employees are believed in this online recruitment.

\section{E-RECRUITMENT AND ITS INFLUENCE IN HR E-RECRUITMENT PROCESS}

E-Recruitment process involves a systematic procedure from sourcing the candidates fromcandidate database to arranging and conducting theinterviewing process that may requires manytechnology, resources and time. A general ERecruitment process is as follows: Identify current need of employment in theorganisation. Posting the advertisement of job vacancy on job board (Online). Managing the response i.e. Applicant database. Shortlisting of Applicant according to jobspecification. Arranging and conducting online interviews (Bychatting, video conferencing etc) and-Decision making regarding further process.

\section{E-RECRUITMENT IN INDIA (CURRENT SCENARIO):}

Despite the challenges of a lower Internet penetration in India, E-recruitment is likely to pick up momentum. A Bangalore-based softwarecompany was in urgent need of professionals withunique set of skills to develop financial planningsoftware. Initially, head hunters were approached,and recruitment ads were placed in newspapers. Theresponse was discouraging, and the company wasable to meet only a handful of people in India, whomatched the requisite skill mix. It decided to opt for an alternativeposting the job on its website andonline databases. The result was instantaneous; thecompany was 
inundated with applications fromacross the country and people from other geographies willing to relocate to India-evidence of the reach of the Internet. Erecruitment facilitates just-in-time hiring. Following are some couple of methods currentlyused in Indian Recruitment Industry. Requirements are now posted regularly on onlinecommunities like Forums, Blogs, and other websiteswhere IT professionals frequent on a day 2-day basis. Individual Recruiters are aggressively using socialnetworking sites like. LinkedIn, Orkut, Facebook, Yahoo-360, Google+ for sourcing qualifiedcandidates. Regarding the interview process, Initial discussionsare all done through telephonic interviews. If theapplicant is in a different city, final discussions aredone through a Video Conference. Recruiters are connected to the applicants in process through diverse communication channelslike online messengers, SMS etc. Online Career events are already being hosted by acouple of Job Portals in India. Job Seekers are also using Social networking sitesactively to meet with the Recruiters online and explore the opportunities. A few companies have extended theirRecruitmentactivities into Virtual worlds like Secondlife.com.

\section{EFFICIENCY OF E-RECRUITMENTSYSTEM:}

\section{Time Efficiency}

Conventional or manual or traditionalrecruitment takes lot of time in recruiting the potential hires. However, the e-recruitment saves lotof time for both employers and job-seekers. E-recruitment bridges the gap between the employersand job seekers. It provides wider scope, choice andopportunities for both.It provides round the clock services. It is indeed win-win for both employers and prospective employees.It helps in tracking the status of the candidates atdifferent stages while hiring.

\section{Cost Efficiency}

The cost is low because there are nomiddlepersons involved.If an employee left the organization,immediately a person can join the organization sothat the work cannot be hampered.

\section{Quality Efficiency}

It filters ineligible and unsuitablecandidates and saves time by 60 per cent of thehiring time for recruiters.It is far better and faster than the conventional methods of recruitment.In a survey (Ireland) 35\% of respondentsfelt that recruiting online increased their ability toattract quality candidates.

\section{SOCIAL MEDIA STRATEGY IN E- RECRUITMENT:}

The use of Social Networking Sites for recruitment is a new field in Human Resource Management. Employers believe that using these sites for online background checks is an acceptable practice for making hiring decisions for getting a quick character sketch of the applicant (Clark \& Roberts, 2010). Schäuble et al. (2008) discuss in their article the potentials of online Social Networking Sites for recruitment based on the network XING, the most famous business networking site in Germany (see figure 1). Profiles in Social Networking Sites allow recruiters to gain information about their education and professional career in general. In addition, recruiters have the possibility to contact potential candidates and communicate with them in a noncommittal manner. By using Social Networking Sites, recruiters can search for possible candidates and build up long term relationships with them. Social Networking Sites like LinkedIn, monster can act as a talent pool with a variety of social capital in the form of young professionals and graduates. Recruiters can filter candidates and search for candidates with special backgrounds. This can lead to a time reduction for the search and can also improve the chance finding the right candidates. Besides this, companies can keep in touch with interns, alumni and so forth. Thus, Social Networking Sites can support the relationship management between companies and possible applicants.

There is only one hard and fast rule to managing a social media strategy, whether you are in consumer advertising or HR, you have to start with a goal in mind. Understanding how your overall corporate social strategy is critical to your team's success. One of the best approaches prevailing in the talent acquisition market is Social Media Hiring. It is very simple and defined as the creation of user generated content that includes email, blogs, instant messages, Facebook, LinkedIn, photo sharing, file sharing and even recruitment technology systems.

Social media has changed how we approach almost everything from life tobusiness. For some company it has a smoother transition in changing to social media hiring. But for most it has been a difficult transition.Question of confidentiality and privacy management, usage, productivity, analytics, and 
Return on Investment (ROI) all get thrown around as roadblocks. But it is hard to argue against social media when Facebook and LinkedIn have more users. However, we should completely rely on LinkedIn and Facebook for our hiring, it might be considered as a part of hiring.

One should understand the tools and tricks that are available which is crucial in this interconnected, savvy and social world. The social phenomenon has raised the recruiting world how to create a strategy to address it through attraction and connection. Which in turn, helps to learn about candidate relationship management.

\section{BUILDING MULTI-FACETED ATTRACTION STRATEGIES}

When it comes to talent acquisition and attraction, it is important to think out of the box. It is the right time to start defining target talent audiences and creating an attraction plan around their specific online candidates. One should be very clear that we should cause benefit to the company, to the job and productivity. For doing it, it may take time for doing research, messaging and reallocation of funds currently spent on traditional methods like job boards.

Online display advertising is now a new trend where it comes with interactive or static images and placed via websites through advertisement network. It helps to portrait our job needs and easily attracts the candidates in strategic manner. Targeting the Niche skills helps the specific candidates helps to collect the information.

Search engine marketing is a form of Internet marketing that seeks to promote websites by increasing their visibility in search engine results through use of paid placement, contextual advertising, social media marketing and its optimization. The search engine optimization (SEO) helps the goal to be relevant and think about search engine strategy. Focus on building a great career and mobile site and optimize them based on searchterms. Then, when it comes to content in your recruitment technology system, build SEO landing pages to help increase visibility of specific jobs in your system. These tactical options discussed open your recruiting machine to untapped target candidates. They are highly targeted, cost effective and quickly deployed.

\section{CONCLUSION:}

Automating the Recruitment Processes helps companies in implementing the Best Practices of recruitment and hiring the best talent available in the market. This leads to better employment opportunities through career websites and provides more effective recruiting tools for selecting suitable candidates. the adoption of e-recruitment is about more than just technology. It is about the recruitment system being able to attract the right candidate, the selection process being based on sound and credible criteria, and the tracking process being able to integrate with existing systems. Perhaps most significantly, erecruitment is about cultural and behavioural change, both within HR and at line management level. the whole process of recruitment depends on the availability of candidates in the market. For every vacant position in the company, it is not viable to spend too much of time and resources. This study has explored the effectiveness of using E-Recruitment in organizations. Online recruitment is also effective in terms of managing talent process that is also considered effective. It has also found that ERecruitment will likely to grow in coming years. Erecruitment has provided some remarkable benefits in terms of cost and efficiency.

\section{REFERENCES:}

1. Ms. D Shahila, " E-recruitment challenges" International Journal of Social science \& Interdisciplinary Research IJSSIR, Vol. 2 (5), MAY 2013, PP.118-12

2. Breaugh, JA, Starke. (2000), "Research on employee recruitment: So many studies, so many remaining questions". Journal of management.

3. Cappali, Peter (March 2001), "Making the most of Online Recruiting", Harvard Business Review.

4. Cober, R.T., Brown, D.J. and Levy, P.E. (2004) "Form, content and function: an evaluative methodology for corporate employment websites". Human Resource Management.

5. Feldman, D. C. and Klaas, S. B. (2002), "Internet job hunting: A field study of applicant experiences with on-line recruiting," Human Resource Management.

6. Lievens, F, Harris.(2002), "Research on Internet recruiting and testing: Current status and future directions." International review of industrial and organizational psychology. 
7. Maarten Veger, JA,(2006) "How does Internet recruitment have effect on recruitment performance?" 4th Twente Student Conference on IT, Enschede, University of Twente.

8. E- Recruitment, Avinash S. Kapse Vishal, Patil S, Nikhil Patil V. International Journal of Engineering and Advanced Technology. (IJEAT) ISSN: 2249 - 8958, April,

9. Lakshmi S.L, E-Recruitment: A boom to the organizations in the competitive world, IOSR Journal of Business and Management (IOSRJBM), e-ISSN: 2278-487X, p-ISSN: @319-7668, PP 25-28, www.iosrjournals.org
10. Masese Omete Fred, Dr.Uttam M. Kinange, effectiveness of E-Recruitment in organization development, Management and Economic Journal ISSN; 2456-2661.

11. Van Hoye, G. and F. Lievens, 2007. "Investigating Web-Based Recruitment Sources: Employee Testimonials versus Word-of-Mouse". International Journal of Selection and Assessment, $15(4)$

12. IBM software - Thought Leadership whitepaper "Recruitment is Marketing".

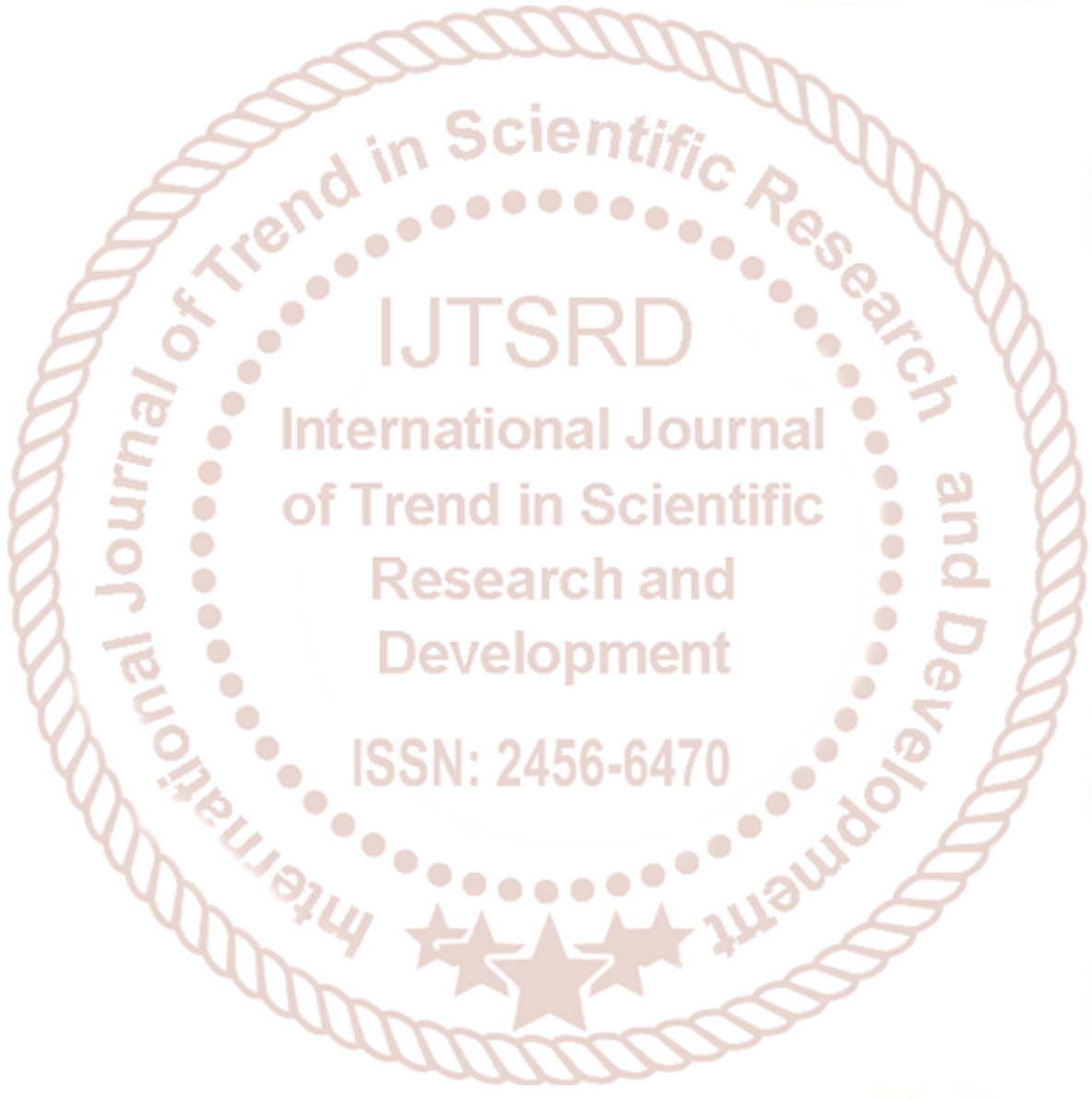

